\title{
Suction as an untapped natural soil reinforcement to reduce embodied carbon in geotechnical structures: the case study of flood embankments in Hamburg area
}

\author{
Raniero Beber ${ }^{1, *}$, Patrick Becker $^{2}$, and Alessandro Tarantino ${ }^{1}$ \\ ${ }^{1}$ Department of Civil and Environmental Engineering, University of Strathclyde, Glasgow, UK \\ ${ }^{2}$ Kempfert Geotechnik GmbH, Hamburg, Germany
}

\begin{abstract}
The commitment to cut $\mathrm{CO}_{2}$ emissions is now becoming a matter of legal obligations in several countries worldwide and the construction industry, one of the main sectors contributing to carbon emissions, is required to develop new approaches for carbon-efficient design. A study was undertaken to examine whether the inclusion of negative pore-water pressures (or 'suction') in the design of a flood embankment could reduce the embodied carbon associate with the construction of a new embankment or the retrofitting of an existing one. The case considered here are the embankments of the tidal Elbe area in Germany that require to be raised because of the new projection of extreme river levels due to climate change. Simple uncoupled water flow and stability analyses were considered to examine the performance of given embankment geometry. The purpose of the study is to examine whether incorporating suction into the design could allow for steeper landside slopes of the flood embankment. This would allow raising the embankment by saving considerable material and, hence, reducing the embodied carbon. At the same time, this would reduce the footprint of the raised embankment, which is a design requirement when flood embankments are embedded in the built environment as it happens in Hamburg.
\end{abstract}

\section{Introduction}

The increase of extreme weather events, both in frequency and magnitude, is a well-established trend observed as a consequence of climate change. In the North Sea, this is anticipated to increase intensity and duration of storm surges and there is a need to safeguard communities from the increased flood hazard.

Earthen structures such as flood embankments are the main asset to manage and mitigate flood risk. Increased extreme sea levels require upgrading flood embankments by raising their crest and, hence, their footprint if the embankments are still designed with the same slope inclination. However, existing earthen structures are often adjacent to the built environment and there is, therefore, no space available to increase the embankment footprint. This calls for new approaches to embankment design, i.e. raising crest level by limiting the increase in embankment footprint.

This would also limit carbon costs. Construction is one of the main sectors responsible for carbon emissions and geotechnical engineers will be challenged to design carbon-efficient geo-infrastructures by making use of environmentally-friendly geomaterials, techniques and reinforcements and developing new design concepts. Suction is commonly neglected in geotechnical design. However, suction is an extraordinary untapped natural 'reinforcement' and, if accounted for in geotechnical design, could significantly contribute to reduce financial and carbon cost of a geostructure.

This paper aims at examining whether, and to what extent, the inclusion of suction in geotechnical design could reduce the embodied carbon. The analysis is developed herein with reference to the design of the upgrade of flood embankments in the Hamburg area in Germany. However, similar concepts could be applied to the retrofitting of existing infrastructures that have to be raised in order to meet new design water levels.

\section{Background}

\subsection{Conventional design of flood embankments}

Hydraulic loading on flood embankments is routinely imposed using a 'steady state' approach (USACE, 2000). The pore water pressure within the embankment is derived by either drawing a flownet or by solving the steady-state water flow equation numerically using easily available software.

The steady-state approach suffers from one major limitation. The implicit assumption is that the river level remains at its peak long enough to establish steady-state conditions. However, the flood defence is only expected to operate as a dam during discrete and sporadic storm events. Storm induced floods typically last for several

\footnotetext{
* Corresponding author: raniero.beber@strath.ac.uk
} 
hours up to a few days. Because the embankment is unsaturated at the onset of the flood event, its hydraulic conductivity is relatively low. As a result, steady-state in the embankment may only be achieved if the flood lasts for several weeks if not months. Indeed, flood embankments tend to remain largely unsaturated during the flood events and the use of steady-state analysis very often results in a largely over-conservative design (Kerkes and Fassett, 2006).

\subsection{Climate change and Embodied carbon}

The commitment to reduce $\mathrm{CO}_{2}$ emissions is now a matter of legal obligation in several countries worldwide. In the $\mathrm{UK}$, around $10 \%$ of the $\mathrm{CO}_{2}$ emissions are associated with the manufacture and transport of construction materials and the operations on site (Construction Excellence, 2008 as cited by UKGBC, 2013). As a result, consulting companies and contractors are under pressure to develop carbon efficient design of geostructures.

Climate change requires industry to change its attitude towards largely over-conservative design, which is becoming less and less acceptable. Innovative methods of analysis are needed to ensure that geostructures are designed in a carbon-efficient fashion. These innovative methods are required for new structures but also to design retrofitting measures.

A joint Defra/EA report (Defra/EA, 2010) on the impact of UK flood infrastructures management schemes on climate change demonstrates that most of the carbon saving in asset construction and maintenance can be achieved through scheme design and engineering.

Embodied carbon savings can be achieved by sourcing local materials (reducing material transport), efficient use of high carbon materials (reducing overall resource/energy use) and enhanced performance-based design that allows reducing the use of material and land occupation.

\section{Methodology}

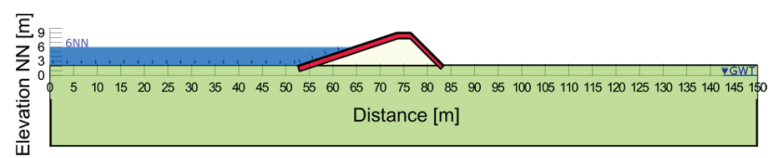

Figure 1 Baseline geometry with highest water level $6[\mathrm{~m}] \mathrm{NN}$ and landside slope 1:1. (NN stands for Normal-Null, a official vertical datum used in Germany)

\subsection{Analysis performed}

The paper explores whether the design of the flood embankment based on transient water flow analysis and accounting for the effect of suction allows increasing the inclination of the landside slope and, hence, reducing the embodied carbon (because of the reduced amount of material used to construct the embankment) and the embankment footprint. To this end, the design based on steady-state analysis with no suction was compared with the design based on transient water flow and assuming the soil to be unsaturated above the phreatic surface. The factor of safety of embankments having landside slope varying from a $1: 3$ up to $1: 1$ ratio $(\mathrm{H}: \mathrm{L})$ was calculated as summarized in Table 1.

\begin{tabular}{c|c|c|c}
\multicolumn{2}{c}{ Table 1 Performed analysis } \\
$\begin{array}{c}\text { H:L } \\
\text { slope } \\
\text { ratio }\end{array}$ & $\begin{array}{c}\text { Slope } \\
\text { Angle } \\
{\left[{ }^{\circ}\right]}\end{array}$ & $\begin{array}{c}\text { Steady-State } \\
\text { analysis no } \\
\text { suction }\end{array}$ & $\begin{array}{c}\text { Transient } \\
\text { analysis with } \\
\text { suction }\end{array}$ \\
\hline $1: 1.00$ & 45.0 & $\mathrm{X}$ & $\mathrm{X}$ \\
\hline $1: 1.25$ & 38.7 & $\mathrm{X}$ & $\mathrm{X}$ \\
\hline $1: 1.50$ & 33.7 & $\mathrm{X}$ & $\mathrm{X}$ \\
\hline $1: 1.75$ & 29.7 & $\mathrm{X}$ & $\mathrm{X}$ \\
\hline $1: 2.00$ & 26.6 & $\mathrm{X}$ & $\mathrm{X}$ \\
\hline $1: 2.50$ & 21.8 & $\mathrm{X}$ & $\mathrm{X}$ \\
\hline $1: 3.00$ & 18.4 & $\mathrm{X}$ & $\mathrm{X}$
\end{tabular}

\subsection{Numerical model}

The Software GeoStudio 2019 was used for the analyses. It includes the module SEEP/W to compute the porewater pressure and the module SLOPE/W to perform the stability analysis using the simplified Bishop method of slices.

Seepage analysis The FEM module SEEP/W was used to analyse two cases distinguished hereafter: i) a steady state analysis assuming saturated condition below the phreatic surface and a virtually dry soil above the phreatic surface and ii) a transient saturated/unsaturated seepage analysis in the embankment and its foundation. The governing equation is the Richards' equation (Richards, 1931), which is written under two-dimensional flow conditions as follows as shown in Eq. 1:

$$
\frac{\partial}{\partial x}\left(k \frac{\partial h}{\partial x}\right)+\frac{\partial}{\partial y}\left(k \frac{\partial h}{\partial y}\right)=\frac{\partial \theta}{\partial t}
$$

where $x$ and $y$ are spatial coordinates, $\theta$ is the volumetric water content, $h$ is the hydraulic head, $k$ is the hydraulic conductivity (as a function of $\theta$ ), and $t$ is the time.

The boundary condition on the riverside was represented by a constant head at $6[\mathrm{~m}] \mathrm{NN}$ (Normal-Null, an official vertical datum used in Germany) for the steady state case (Fig. 1) and by a time-dependent hydraulic head (i.e. the chain tide storm L3) taken from the Hamburg port authority guidelines for design as shown in Fig. 2.

A constant head at the $0 \mathrm{NN}[\mathrm{m}] \mathrm{y}$-coordinate was assigned the vertical boundary on the landside. The bottom boundary was modelled as impermeable. The distance of the landside vertical boundary from the toe of the embankment was set to $52-67 \mathrm{~m}$, wide enough so that the pore-water pressure distribution up to $10 \mathrm{~m}$ from the toe of the embankment was not affected by the boundary condition on the landside. The crest of the embankment, the landside slope and the ground surface were modelled as potential seepage faces, i.e. pore-water pressure can never exceed atmospheric pressure. The condition prior to the transient analysis simulating the storm surge has been obtained by a two-step process, i) a steady-state seepage analysis with hydraulic head on the river side head set to $0[\mathrm{~m}] \mathrm{NN}$ followed by ii) a transient analysis where the 
water level associated with the normal tide regime was imposed for one year.

\section{L3-Chain flood design tide}

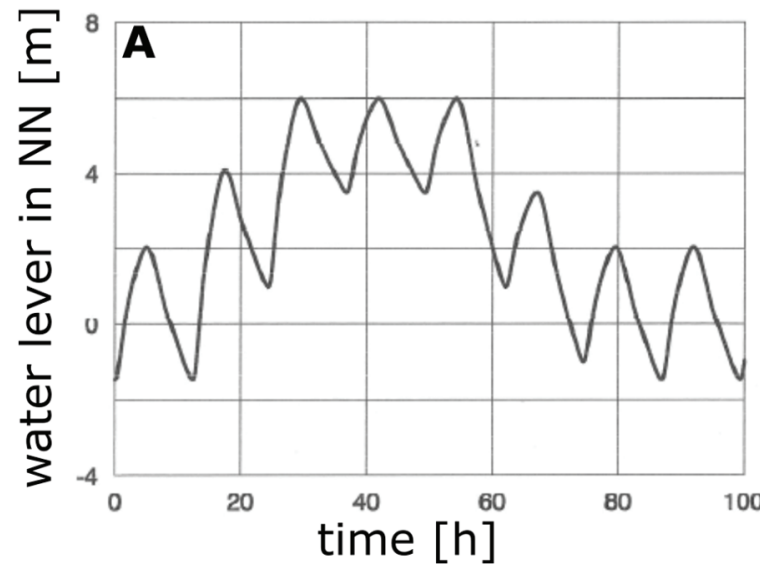

Figure 2 L3-chain tide used in the transient analysis, (NN stands for Normal-Null, a official vertical datum used in Germany), after HPA 2008, Technische Rahmenbedingungen (TR HWSBau)

A constant time step of 30 min was used for both, the $\sim 1$-year tide record (12774 time steps) and the entire duration of the storm surge L3 seepage simulation (100 h). An unstructured mesh of quadrilateral and triangular elements was adopted for the entire domain. The mesh density in the regions where higher gradients develop was optimised by reducing the element size until no significant change in simulated pore-water pressure was observed ( $\sim$ $0.5 \mathrm{kPa}$ ). Elements with size equal to $0.1 \mathrm{~m}$ were adopted for the embankment cover and elements with size equal to $0.5 \mathrm{~m}$ were used for the embankment core and foundation layers.

Stability analysis_The stability analysis was carried out using Bishop's simplified method (Bishop, 1955). The iterative procedure to calculate the Factor of Safety was completed with the module SLOPE/W. The pore-water pressures from the steady-state seepage analysis in one case and from the transient seepage analysis in the other case were used to calculate the evolution of the Factor of Safety over the duration of the storm surge event. To account for the effect of suction in shear strength, the unsaturated shear strength model implemented by the software based on Vanapalli et al. (1996) was considered appropriate (Tarantino \& El Mountassir, 2013). The critical slip surface was assumed circular and then refined with the optimisation algorithm based on the segmental technique.

\subsection{Material hydro-mechanical parameters}

Material properties were derived from a dataset made available by the Hamburg Geological Survey (Geologisches Landesamt Hamburg, http://ingdata.hamburg.de/) reporting hydraulic and mechanical properties of the materials forming the embankments and their foundations in the Elbe river harbour. In particular, the following 3 materials were considered:

- Klei, clayey sandy silt used as a cover to impermeabilize the embankment;

- Clean sand, mainly used to construct the embankment core

- Silty sand, used as foundation.

For these three materials, the following parameters were retrieved: particle size distribution, effective friction angle from CU-TRX tests, saturated hydraulic conductivity from permeability tests. The parameters used in the numerical model are summarised in Table 2. Only for the Klei cover a cohesion c' equal to $10 \mathrm{kPa}$ has been used.

\begin{tabular}{|c|c|c|c|c|c|c|}
\hline \multirow{2}{*}{ Material } & \multirow{2}{*}{$\begin{array}{l}\text { Function for } \\
\text { embankment }\end{array}$} & $D_{50}$ & $\gamma_{\text {DRY }}$ & ${ }^{\gamma_{\mathrm{SAT}}}$ & $\varphi$, & $\mathbf{K}_{\text {sat }}$ \\
\hline & & {$[\mathrm{mm}]$} & {$\left[\mathrm{kN} / \mathrm{m}^{3}\right]$} & {$\left[\mathbf{k N} / \mathbf{m}^{3}\right]$} & $I^{\circ}$ & {$[\mathrm{m} / \mathrm{s}]$} \\
\hline Klei & cover & 0.01 & 12.5 & 17.5 & 25 & $1 \mathrm{e}-8$ \\
\hline $\begin{array}{l}\text { Clean } \\
\text { Sand }\end{array}$ & core & 0.7 & 17 & 20 & 36 & $1 e-5$ \\
\hline $\begin{array}{l}\text { Silty } \\
\text { Sand }\end{array}$ & foundation & 0.3 & 18 & 20 & 33 & $1 e-6$ \\
\hline
\end{tabular}

Table 3 SWRC van Genuchten parameters

\begin{tabular}{l|c|c|c}
\multicolumn{1}{c}{ Material } & $\mathbf{a}$ & $\mathbf{~ m}$ & $\mathbf{n}$ \\
\cline { 2 - 4 } & {$\left[\mathrm{kPa}^{-1}\right]$} & $-\mathrm{I}$ & $\mathrm{H}$ \\
\hline Klei & 0.0100 & 0.4118 & 1.7 \\
\hline Clean Sand & 0.1429 & 0.6667 & 3 \\
\hline Silty Sand & 0.1000 & 0.5000 & 2
\end{tabular}

The soil water retention curve SWRC were estimated using the van Genuchten (1980) function with the parameters in Table 3 whereas the hydraulic conductivity function was derived from eq. 2 and 3 based on the SWRC parameters:

$k_{r}(\theta)=\sqrt{\theta_{e}}\left[1-\left(1-\theta_{e}{ }^{1 / m}\right)^{m}\right]^{2}$

$k_{r}(\theta)=\frac{k(\theta)}{k_{s a t}}$

where: $k(\theta)=$ hydraulic conductivity function, $k_{r}(\theta)=$ relative hydraulic conductivity function, $k_{\text {sat }}=$ saturated hydraulic conductivity.

\section{Results}

Two flood embankment designs were analysed, i) flood embankment with traditional mild slope of 1:3 designed using conventional steady-state water flow analysis and neglecting suction and ii) flood embankment with steep 1:1 slope designed on the basis of the transient water flow analysis taking suction into account.

\subsection{Conventional design - Steady-state water flow without suction}

Figure 3 shows the pore-water pressure distribution for the case of steady-state water flow and 1:3 slope. The contrast in saturated hydraulic conductivity between the Klei cover and the embankment core material deviates the flow lines and lower the level of the phreatic surface within the sand embankment core with respect to the river 
level. The phreatic surface intersects the landside slope and generates positive pore-water pressure at the embankment toe.

The failure surface associated with lower Factor of Safety $(\mathrm{FoS})$ is located at the toe of the landside slope due to the higher pore-water pressures developing at the toe (Figure 3). The value of 1.69 for the FoS shows that there is room to increase the inclination of the landside slope even for the case where water flow is analysed under steady-state conditions. The evolution of the FoS against the inclination of the landside slope is reported in Figure 5. As expected, the FoS decreases with the inclination of the landside slope. For a slope ratio of $1: 1.5$, the FoS is 0.95 (just below unity).

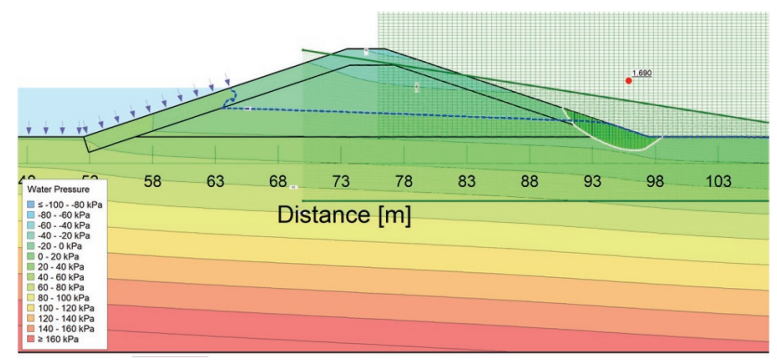

Figure 3 Pore pressure distribution, failure surface associated with minimum FoS, and grid of centres of rotation of failure surfaces explored for the case steady-state analysis with water level at $6[\mathrm{~m}] \mathrm{NN}$

\subsection{Advanced design - Transient water flow with suction}

Figure 4 shows the pore-water pressure distribution for the case of transient-state water flow and 1:1 slope. After the steady-state initial condition at $0[\mathrm{~m}] \mathrm{NN}$, followed by $\mathrm{a} \sim 1$ year of tidal cycles, the storm surge generates very little penetration of the waterfront within the embankment. The embankment toe on the landside remains unsaturated with the phreatic surface located $\sim 1$ $\mathrm{m}$ below the embankment toe.

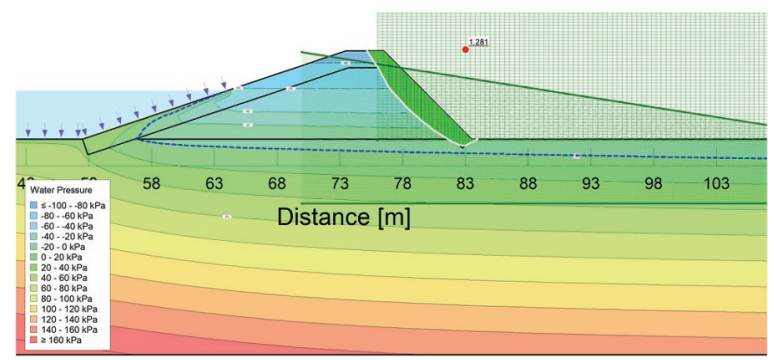

Figure 4 Pore pressure distribution, failure surface associated with minimum FoS, and grid of centres of rotation of failure surfaces explored numerically for the case transient analysis the chain tide L3 as a load (snapshot@ 53.5 h)

Due to limited increase in pore-water pressure within the embankment during a chain storm event, the FoS appears to be significantly higher than unity even for a slope 1:1. The factor of safety also benefited from the inclusion of suction in the shear strength model. The critical failure surface for the case of the steepest slope investigated numerically (1:1) involves the entire landside slope of the embankment and half of its crest with a FoS of 1.28. The evolution of the FoS for different inclinations of the landside slope is reported in Figure 5. The FoS decrease from a value of 2.79 for the $1: 3$ slope to 1.28 for the $1: 1$ slope.

\section{Discussion}

\subsection{Over conservative design, how much space of improvement?}

To better understand the benefit of the proposed design approach and how conservative is the traditional approach, Figure 5 reports the variation of the FoS with the inclination of the landside slope for the two cases examined. The curve associated with steady-state water flow rapidly intersect the value $\mathrm{FoS}=1$ and tends to level off at inclinations of 1:1.5. For the transient water flow analysis, the FoS decrease monotonically but remains significantly higher than unity. The comparison between the FoS under steady-state and transient state water flow shows that the steady-state analysis underestimates the factor of safety by about $70 \%$, which indicates significant over-conservative design.

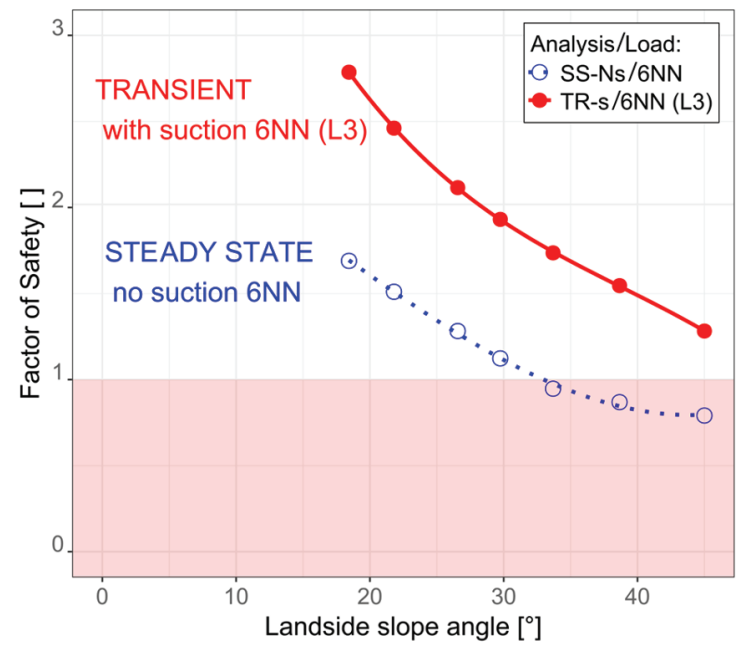

Figure 5 Variation of the factor of safety with inclination of the landside slope for the case of steady-state (dotted line) and transient state (solid line) water flow analysis.

The steady-state water flow analysis implicitly assumes that the storm surge water level persists for a period of time long enough to establish steady-state conditions. However, it is clear by comparing Figure 3 and Figure 4 that this condition is difficult to be met in a realistic scenario due to the transient nature of the storm surge. The storm surge water level deviates from the tide in normal conditions for a period of $55 \mathrm{~h}$, not long enough to reach a steady state seepage through the embankment. This is in line with the study of Kerkes and Fassett (Kerkes and Fassett, 2006). They analysed a homogenous sand embankment of comparable size to the one of this work 
and similar hydraulic conductivity of sand $\left(k_{\mathrm{sat}}=5 \cdot 10^{-6}\right.$ $\mathrm{m} / \mathrm{s}$ ). They concluded that at least $72 \mathrm{~h}$ were needed to reach nearly steady state condition, which would be still be longer than the $55 \mathrm{~h}$ of the design storm surge for the Hamburg flood embankments. The transient water flow analysis shows that the steady-state assumption is unrealistic as the waterfront hardly penetrates the embankment core due to the low hydraulic conductivity of the Klei cover and embankment core sand associated with partial saturation. This keeps the phreatic surface far from the landside toe of the embankment where failure surface tends to develop.

\subsection{Implications for embodied carbon and footprint of geotechnical infrastructures}

Embodied carbon

Based on a case study of Waltham Abbey in Essex UK developed by Defra/EA (2010), Beber et. al. (2020) estimated a embodied carbon for a flood embankment in the range $57-65 \mathrm{~kg}$ of $\mathrm{CO}_{2} \mathrm{e} / \mathrm{m}^{3}$. The total computed emission was attributed to material transport, plant emission, personnel travel, waste removal, and quarried material, the latter accounting for $76-82 \%$ of the overall carbon cost.

For the case where $1 \mathrm{~km}$ of embankment has to be upgraded from a height of $5 \mathrm{~m}$ to $7 \mathrm{~m}$, the original crosssectional area of $90 \mathrm{~m}^{2}$ would increase to $168 \mathrm{~m}^{2}$ for the case of conventional design (section 4.1, SS-Ns) or just to $119 \mathrm{~m}^{2}$ using the transient analysis suction-based approach (section 4.2, TR-s), i.e. the cross-section would increase by $87 \%$ and $32 \%$ respectively. This would result in an increase of $4510-5074 \mathrm{tCO}_{2} \mathrm{e} / \mathrm{km}$ for the case of the more conservative conventional design (SS-Ns) and 1677-1886 $\mathrm{tCO}_{2} \mathrm{e} / \mathrm{km}$ for the proposed design approach (TR-s). The difference between the two design approached would be 2833-3187 $\mathrm{tCO}_{2} \mathrm{e} / \mathrm{km}$, which roughly corresponds to $11-13$ million car $/ \mathrm{km}$ or more than 3400-3800 flights London-New York.

This would just be the cost per km, which should be then multiplied by the length of the flood embankments, which is $130 \mathrm{~km}$ for the Hamburg flood defence system.

\section{Footprint savings}

Increasing the inclination of the landside slope does not only reduce the amount of material used to raise the embankment and the embodied carbon thereof but also allow reducing the embankment footprint. In turn, this allows reducing i) the habitat suppression with the subsequent need for habitat compensation and recreation, and ii) land expropriation costs which might be high in a tight build environment.

The proposed design (TR-s) leads to an embankment footprint $30 \%$ smaller than the one associated with traditional design (SS-Ns) for the case of a newly built embankment. For the case of an embankment retrofitted with a $2 \mathrm{~m}$ increase of the crest elevation, the footprint saving ranges between $40 \%$ and $50 \%$. This means that the extent of compensatory habitat that needs to be created for a project could be drastically reduced. The impact on the adjacent habitat and the time required to restore its ecological function could also be reduced.

A survey of land values on real estate market in Hamburg reveals that at the time of writing (2020) the price of land with building permits is around 250-400 $\mathrm{EUR} / \mathrm{m}^{2}$ in the harbour area and Wilhelmsburg island on the south side of the river Elbe (LBS, 2020). The price rises sharply above $600 \mathrm{EUR} / \mathrm{m}^{2}$ on the north bank facing the harbour, this area, however, is mostly protected by hard structures against flood water (i.e., retaining wall, sheet pile walls). The Hamburg earthen flood-protection infrastructures are mainly located in the relatively cheaper areas but every meter square of land that needs to be occupied by the embankment would rapidly increase the overall cost of the project, especially considering the linear extension of these infrastructures.

Let us consider the case where $1 \mathrm{~km}$ of embankment has to be upgraded by increasing the elevation of its crest from $5 \mathrm{~m}$ to $7 \mathrm{~m}$ and let us assume the average price of land is $325 \mathrm{EUR} / \mathrm{m}^{2}$. The TR-s approach including suction would allow raising the embankment without increasing its footprint whereas the SS-Ns approach considering steadystate analysis would require extending the embankment footprint by $+12 \mathrm{~m}$. This would lead to an increase in cost due to expropriation equal to 3.9 million EUR/ $\mathrm{km}$. For the case of a newly built embankment of $7 \mathrm{~m}$ height, the difference would become equal to 4.5 million EUR $/ \mathrm{km}$.

\section{Conclusions}

The paper has shown that the traditional steady-state water flow analysis used to design flood embankments can significantly underestimate the Factor of Safety and, hence, generates significant overdesign.

If water flow is simulated with transient analysis and suction is included in the shear strength model, the embankment can be designed with a much steeper slope on the landside.

To quantify the benefit of increasing the slope from 1:3 to $1: 1$, we considered the scenario whereby the embankment has to be raised from $5 \mathrm{~m}$ to $7 \mathrm{~m}$ in height.

The increase in footprint would be $12 \mathrm{~m}$ for the case of steady-state flow design however a decrease of $2 \mathrm{~m}$ from the original embankment footprint results when transient water flow analysis is considered.

In the Hamburg area, this would lead to a saving of 4.5 million EUR $/ \mathrm{km}$ due to the reduced costs of expropriation. The embodied carbon savings would of the order of 2800-3200 $\mathrm{tCO}_{2} \mathrm{e} / \mathrm{km}$.

If a new embankment has to be built, a 1:1 slope would allow a saving of $66 \%$ of the material for the embankment shoulder compared to the 1:3 slope.

The authors wish to acknowledge the support of the European Commission via the Marie Skłodowska-Curie Innovative Training Networks (ITN-ETN) project TERRE 'Training Engineers and Researchers to Rethink geotechnical Engineering for a low carbon future' (H2020-MSCA-ITN-2015-675762). 


\section{References}

1. Beber, R., Becker, P. and Tarantino, A., Retrofitting of river embankments in a climatic-change scenario: the case study of Elbe harbour in Hamburg. To be submitted to Geomechanics for Energy and the Environment (2020)

2. Bishop, A.W., The use of the slip circle in the stability analysis of slopes. Geotechnique, 5(1), pp.717 (1955)

3. Construction Excellence Construction and Sustainable Development - Plain English, (as cited by UKGBC, 2013) (2008)

4. Defra/EA Joint R\&D FCERM, Understanding the Impact of Flood and Coastal Erosion Risk Management on the Causes of Climate Change. Report FD2622/TR (2010)

5. Esteves, L.S, Thomas, K. Managed realignment in practice in the UK: results from two independent surveys. Journal of Coastal Research. 70:407-13 (2014)

6. GeoSlope Seepage modelling with SEEP/W 2012 An engineering methodology, 4th Ed., GeoSlope International, Alberta, Canada (2019)

7. Hamburg Port Authority, Technische Rahmenbedingungen (TR HWS-Bau) (2008)

8. LBS, LBS-Immobilienmarktatlas Hamburg und Umland 2020, report https://www.lbs.de/ (2020)

9. Kerkes, D.J. and Fassett, J.B. Rapid drawdown in drainage channels with earthen side slopes, in Proceedings of the ASCE Texas Section Spring Meeting, 19th - 22nd April 2006, Beaumont, Texas (2006)

10. Richards, L.A., Capillary conduction of liquids through porous mediums. Physics, 1(5), pp.318-333 (1931)

11. Tarantino, A. and El Mountassir, G., Making unsaturated soil mechanics accessible for engineers: Preliminary hydraulic-mechanical characterisation \& stability assessment. Engineering geology, 165, pp.89-104. (2013)

12. USACE US Army Corps of Engineers - EM 1100-21913 Design and Construction of Levees - Engineer Manual, published by USACE (2000)

13. van Genuchten, M.T. A closed form equation for predicting the hydraulic conductivity of unsaturated soils, Soil Sci. Soc. Am. J., vol. 4, pp 892-898 (1980)

14. Vanapalli, S.K., Fredlund, D.G., Pufahl, D.E. and Clifton, A.W. Model for prediction of shear strength with respect to suction, Can. Geotech. J., vol. 33, pp 379-392 (1996) 